\title{
A TAXONOMIC STUDY OF A NEW GENUS AND THREE NEW SPECIES OF EULOPHIDAE (HYMENOPTERA: CHALCIDOIDEA) FROM INDIA
}

\author{
T.C. Narendran ${ }^{1}$, M. Sheeba ${ }^{2}$ and M.C. Jilcy ${ }^{3}$ \\ 1,2,3 Systematic Entomology Laboratory, Department of Zoology, University of Calicut, Thenjipalam, Kerala 673635, India \\ Email: ${ }^{1}$ drtcnarendran@yahoo.com
}

\begin{abstract}
A new genus Hayatiola Narendran with the type species Hayatiola macrocephala $s p$. nov. Narendran and two other species, viz., Omphalentedon dasi sp. nov. Narendran \& Sheeba and Platyplectrus yarensus $s p$. nov. Narendran \& Jilcy are described from India. Hayatiola resembles Petiolacus Boucek in general appearance but differs from it in having different proportion of antennal segments, different antennal formula, in having distinct plicae and in several other characters. Omphalentedon dasi differs from $\mathrm{O}$. longus Girault mainly in different antennal formula and in different size and proportion of antennal segments. Platyplectrus yarensus differs from all other described species of Platyplectrus in very many characters.

KEYWORDS

Chalcidoidea, Eulophidae, Hayatiola gen. nov., Hayatiola macrocephala sp. nov., Hymenoptera, India,

Omphalentedon dasi $s p$. nov., Platyplectrus yarensus $s p$. nov.,

\section{Abbreviations}

DZUC - Department of Zoology, University of Calicut, Kerala, India; F1-F4 - Funicular segments 1 to 4; MV - Marginal vein; OD - Hind ocellar diameter; CC - Costal cell; PMV - Postmarginal vein; POL - Postocellar distance; SMV - Submarginal vein; STV - Stigmal vein; ZSIK - Western Ghat Regional Station, Zoological Survey of India, Kozhikode, Kerala, India.
\end{abstract}

In our studies on the eulophid fauna of India we came across three interesting taxa which are hitherto unknown to science. The new genus Hayatiola Narendran does not fit into any of the genera of the family Eulophidae so far listed by Noyes (2004). It does not fit in to any of the keys of Boucek (1988), Schauff et al. (1997) and Hayat (1985). The genus Omphalentedon Boucek is reported for the first time from the Oriental region with the description of a new species Omphalentedon dasi Narendran and Sheeba from West Bengal, India. The new species Platyplectrus yarensus Narendran and Jilcy differs from all other known species from India and Sri Lanka. Their differences with related species are discussed. All the types are temporarily deposited in DZUC and eventually will be transferred to ZSIK.

\section{Hayatiola Narendran gen. nov.}

Type species: Hayatiola macrocephala Narendran sp. nov.

\section{Etymology}

Named after Prof. M. Hayat of Aligarh Muslim University who collected the specimen. Feminine gender.

\section{Diagnosis}

Head large with post occiput concave accommodating pronotum; antennal formula 11333; gena strongly converging; mesoscutum shorter than scutellum, scapula with 5-6 setae; scutellum with five admarginal setae on either side; axillae hardly advanced; propodeum with a double median carinae, enclosing a microsculptured median area; plicae distinct; petiole flat and microsculptured.

\section{Discussion}

This new genus belongs to the subfamily Eulophinae. It comes near Petiolacus Boucek (Boucek, 1988) in having a long petiole; slender body, excavated occiput, clypeus poorly delimited, mouth small, genae strongly converging, scape exceeding vertex, mesoscutum with vague notauli; axillae hardly advanced, elongate scutellum and propodeum subhorizontal. However, it differs from Petiolacus in having: (i) Pedicel not small, $0.75 \mathrm{x}$ as long as F1 (In Petiolacus pedicel very short, shorter than half length of F1); (ii) Scrobe distinct (indistinct in Petiolacus); (iii) Funicle 3 segmented and clava 3 segmented (in Petiolacus funicle 4 segmented and clava 2 segmented); (iv) Pronotum hidden by head (in Petiolacus pronotum longer than mesoscutum and well visible); (v) Propodeum with a double median carinae enclosing a microsculptured median area (in Petiolacus propodeum with a single median carina); (vi) Plicae distinct (plicae absent in Petiolacus); (vii) Submedian area of propodeum reticulate (smooth in Petiolacus); (viii) Hind coxa without raised transverse rugae (with raised transverse rugae on dorsal side in Petiolacus); (ix) Forewing not bifaciate (forewing bifaciate in Petiolacus); (x) Forewing 2.4x as long as wide (in Petiolacus forewing $2.8 \mathrm{x}$ as long as wide); (xi) CC shorter than MV (in Petiolacus CC longer than MV); (xii) petiole flat on dorsal side with microsculptures (in Petiolacus petiole humped and with a median raised ridge, not microsculptured); (xiii) Scutellum with five weak setae in an irregular longitudinal row on either margin (in Petiolacus scutellum entirely different, somewhat like elachertini).

\section{Hayatiola macrocephala Narendran sp. nov.}

$$
\text { (Figs. 1-5) }
$$

\section{Material examined}

Holotype: Female, vi.1983, Aligarh, Uttar Pradesh, India (27054'N-7804'E), coll. M. Hayat (DZUC \# Moef 5595).

\section{Etymology}

Named after its large head.

\section{Description}

Female: Length $1.17 \mathrm{~mm}$. General body colour brown; eye grayish-yellow; ocelli pale yellow; antenna pale brownish- 


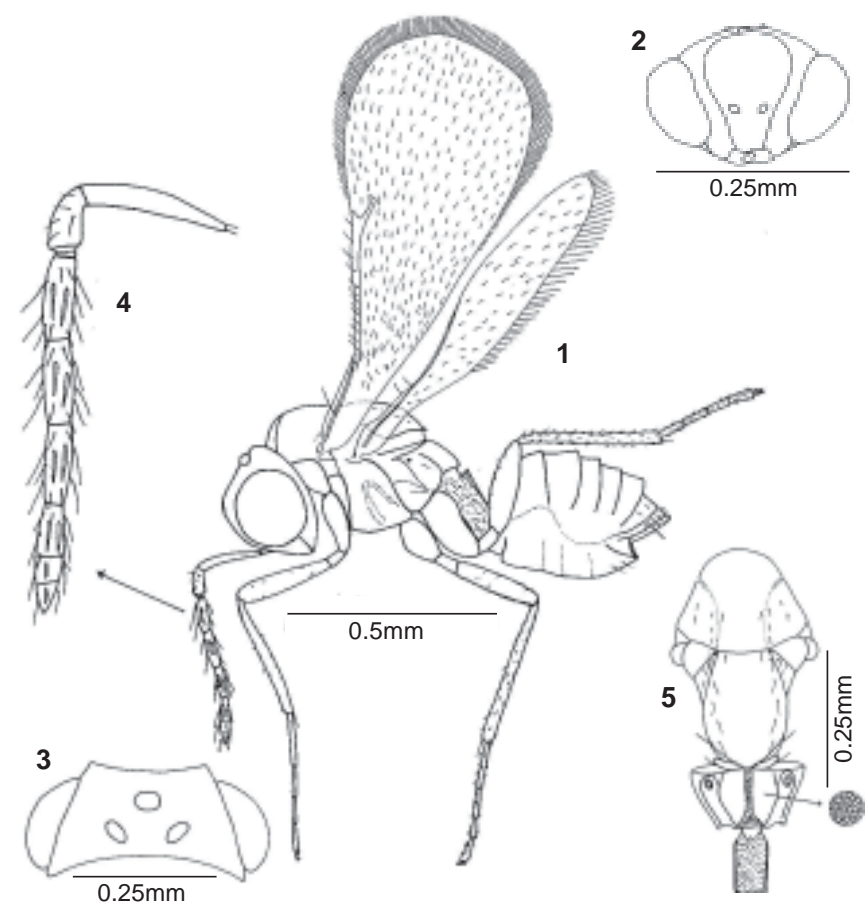

Figures 1-5. Hayatiola macrocephala Narendran sp. nov. (Female)

1 - Body profile; 2- Head front view; 3 - Head dorsal view; 4 - Antenna; 5 - Mesoscutum, scutellum, propodeum and petiole - dorsal view.

yellow except black clava; legs including coxae yellow except pale brownish yellow fourth tarsal segment and pretarsi; wings hyaline with veins and pilosity pale brown.

Head: Not collapsing in dried specimens; relatively large; width in anterior view 1.46x its length; width in dorsal view 1.19x its maximum length, vertex flat (Fig. 3), reticulate with sparse, short pilosity; lower clypeal margin weakly but distinctly emarginate; mandibles bidentate; scrobe deep, margin raised; POL equal to OOL; OOL 1.57x OD; eyes bare, converging towards ventral part (Fig. 2); eye height in side view a little longer than its width (18:16), 3.6x length of malar space; malar sulcus complete, straight without a basal fovea below eye; occiput concave so that posterior part of head completely cover pronotum; antennal toruli inserted well above lower ocular line (Fig. 2), a little below middle; antennal formula 11333; scape broader towards apical part (Fig. 4); slightly exceeding level of vertex, distinctly longer than clava; relative length: width of antennal segments (Fig. 4): Scape $=35: 5$ (maximum width); pedicel $=15: 8 ; \mathrm{F} 1=20: 7 ; \mathrm{F} 2=$ 20:7; F3 = 19: 6.5; Clava $=26: 6.5$; clava without an apical specula.

Mesosoma: Pronotum hidden by posterior excavation of head; mesoscutum distinctly reticulate, notauli weak, but traceable up to scuto-scutellar groove, with 1 pair of setae; each scapula with 5 setae; all setae relatively small, weak (Fig. 5); scutellum longer than mesoscutum (40:36), a little over 1.3x as long as its width, with 4 admarginal weak setae (Fig. 5); submedian and sublateral grooves absent; axillae slightly advanced anteriorly;

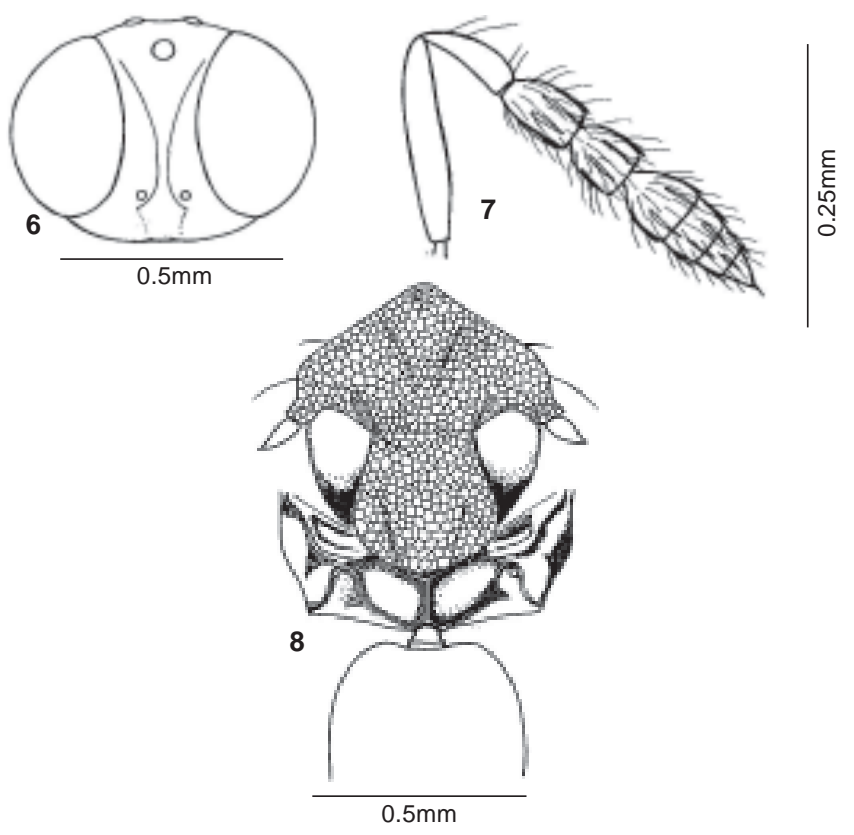

Figures 6-8. Omphalentedon dasi Narendran \& Sheeba sp. nov. (Female)

6 - Head front view; 7 - Antenna; 8 - Part of mesosoma and part of gaster - dorsal view

dorsellum indistinct; propodeum relatively large as long as half of scutellum, with a double median carinae with a median reticulate groove; submedian area reticulate; propodeal spiracle exposed, separated from metanotum by about half its diameter; plical carinae present. Forewing (excluding fringe) $2.4 \mathrm{x}$ as long as wide; relative measurements of forewing, $\mathrm{CC}$ and veins as follows: $\mathrm{CC}=22 ; \mathrm{MV}=31 ; \mathrm{PMV}=2 ; \mathrm{STV}=6$, marginal fringe $=$ 4; speculum mostly setose with a relatively small asetose area, closed behind by setae (Fig. 1); all coxae smooth and shiny.

Metasoma: Petiole as long as hind coxa, a trifle longer than propodeum, with a narrow neck anteriorly; side margins carinate, both dorsal and lateral parts distinctly microsculptured; gaster shorter than mesosoma (39:45); one cercal seta on either side slightly longer than others; not conspicuous; hypopygium well exceeding middle level of gaster.

Male: Unknown.

Host: Unknown.

Omphalentedon dasi Narendran \& Sheeba sp. nov. (Figs. 6-8)

\section{Material examined}

Holotype: Female, 5.iii.2000, Balurghat, West Bengal, India $\left(25^{\circ} 14^{\prime} \mathrm{N}-88^{\circ} 46^{\prime} \mathrm{E}\right)$, coll. B.K. Das (DZUC \# Moef 4235).

\section{Etymology}

Named after Dr. B.K. Das who collected the species. 


\section{Description}

Female: Length $2.83 \mathrm{~mm}$. Bright metallic green with violet tinge on area near front ocellus on either side; apical part and sides of gaster slightly darker; legs except fore coxae and basodorsal part of hind coxae, pedicel, scape and petiole pale yellowishwhite; other antennal segments pale brownish-yellow; eye pale brownish-yellow; ocelli pale brownish-red; wings hyaline and veins pale yellow, pilosity pale yellow.

Head: Width in anterior view 1.38x its length; width in dorsal view 2.2x its median length; POL a little longer than OOL (5:4) in dorsal view; OOL subequal to OD; frons narrow; occiput excavate, vertex and upper frons with relatively long setae; eyes relatively large (Fig. 6), densely pilose; eye length $1.13 x$ its width, $13 \mathrm{x}$ as long as malar space; malar sulcus indistinct or absent; frontofacial sulci as in figure 6; antennal toruli situated a little above lower level of eye margin; antennal formula 11023; scape not reaching front ocellus, a little longer than clava; pedicel a little longer than F1 (17:14); clava a little longer than F2 + F3; relative length: width of antennal segments : scape $=$ 34: 6; pedicel $=17: 6 ; \mathrm{F} 1=13: 8 ; \mathrm{F} 2=12: 10 ;$ clava $=32: 11.5$.

Mesosoma: With distinctly raised and close reticulation on mesoscutum (including scapulae) and scutellum; anterior part of pronotum with cross reticulations or some what scaly; notauli not very distinct; scutoscutellar suture straight; mesoscutum and scutellum without a median sulcus; sides of scutellum rounded; propodeum large, smooth, with median carina and parallel plicae which turn posteriorly; petiole small but distinct. Forewings $1.85 \mathrm{x}$ as long as broad; relative lengths of $\mathrm{CC}$ and veins: $\mathrm{CC}=29 ; \mathrm{SMV}=27 ; \mathrm{MV}=26 ; \mathrm{PMV}=2 ; \mathrm{STV}=$ 6; marginal fringe about $0.7 \mathrm{x}$ as long as STV; speculum closed behind by a line of setae; SMV with two dorsal setae; midtibial spur a little shorter than midmetatarsus (6:7).

Metasoma: Petiole transverse; gaster distinctly longer than mesosoma, subequal in length to combined length of head + mesosoma; hypopygium slightly exceeding middle of gaster.

Male: Unknown.

Host: Unknown.

Remarks: This new species differs from the only known species
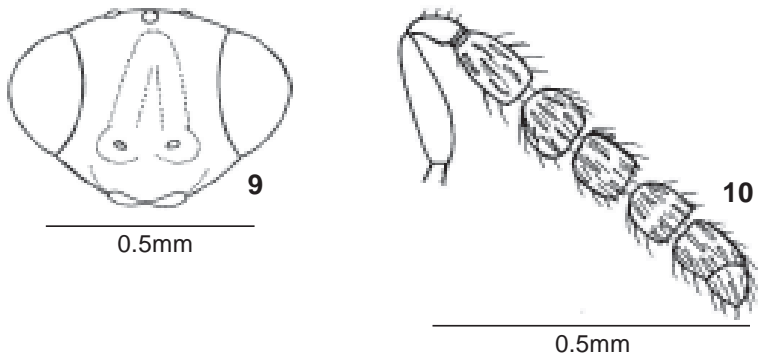

Figures 9-10. Platyplectrus yarensus Narendran \& Jilcy sp. nov. (Female) 9 - Head front view; 10 - Antenna of the genus Omphalentedon longus described by Girault (1915) from Australia in having: (i) Female antenna with two funicular segments and three segmented clava (in O. longus female antennal funicle 3 segmented and clava 2 segmented); and (ii) size and proportions of antennal segments differ in two species, besides many other features.

\section{Platyplectrus yarensus Narendran \& Jilcy}

(Figs. 9-10)

\section{Material examined}

Holotype: Female, 8.i.2004, Vandiperiyar, Idukki District, Kerala, India $\left(9^{\circ} 35^{\prime} \mathrm{N}-77^{0} 5^{\prime} \mathrm{E}\right)$, coll. T.C. Narendran \& party (DZUC \# Moef 1881).

\section{Etymology}

A combination of letters.

\section{Diagnosis}

Female: Length $2.18 \mathrm{~mm}$. Black except following areas: eye brick red with margin paler; ocelli pale reflecting yellow; antenna light brown except pale yellow scape; legs yellow with hind coxa black and hind femur yellowish-brown (apex paler); tegula yellowish-brown, with an subtriangular yellowish-brown spot; gaster black with basodorsal (T1 to T3) pale brownish-yellow, base of gaster brownish-yellow on sides also; mesosoma and metasoma without metallic refringence; wings hyaline, veins and pilosity pale brown.

Head: Width in anterior view $1.44 \mathrm{x}$ its length; width in dorsal view $2.25 \mathrm{x}$ its median length; inter ocular distance $2.6 \mathrm{x}$ eye width in dorsal view; malar space $0.3 \mathrm{x}$ eye height in side view; eye moderately pilose; malar sulcus distinct; epistomal sulcus faint; POL a little over OOL (5:4); frons and vertex mostly smooth and shiny; frons not clearly separated from vertex by transverse lamina; occipital carina present, post occipital carina absent.; antennal formula 11242; scape not reaching front ocellus; F1 $1.44 \mathrm{x}$ as long as pedicel, $1.63 \mathrm{x}$ as long as broad, F2 to F4 subequal in length and width, each shorter than F1; clava subequal to length of F1 (excluding apical seta).

Mesosoma: Pronotum not carinated, rounded in front; pronotum and mesoscutum coriaceous punctate with scattered thick white setae; axillae mostly smooth and shiny; scutellum moderately and uniformly reticulate, not rugose in the middle; lateral furrows deep but not regularly foveolate; converging posteriorly to meet in the middle; dorsellum weakly reticulate; propodeum smooth, well developed median carina and basal cup; plicae distinct. Forewing $2.2 \mathrm{x}$ as long as wide; ratio of CC and veins: $\mathrm{CC}=15 ; \mathrm{SMV}=11 ; \mathrm{MV}=18 ; \mathrm{PMV}=11 ; \mathrm{STV}=6$; speculum small, closed behind by a line of setae. Hind coxa weakly reticulate on dorsal side and distinct and strongly reticulate on latero-ventral part; longer spur of hind tibia distinctly shorter than first two tarsal segments together (15: 18).

Metasoma: Petiole short, transverse, metasoma shorter and narrower than mesosoma; hypopygium reaching very near apex 
A key to separate the Indian species of Platyplectrus is as follows:

1. Petiole long, more than $2 x$ as long as wide; head bluish-green and shining; pronotum without transverse carina Platyplectrus viridiceps (Ferriere) 2

2. $\quad \mathrm{CC}$ longer than MV; coxae concolorous with body (black); notauli not deep, weakly represented; propodeal spiracle elongate, oval; propodeum $0.75 x$ length of scutellum ........... Platyplectrus kuriani Wijesekara \& Schauff

CC shorter than MV; fore and mid coxae not concolorous with body; notauli deep \& distinct; propodeal spiracle rounded; propodeum $0.33 x$ as long as scutellum

Platyplectrus yarensus Narendran \& Jilcy sp. nov.

of gaster.

Male: Unknown.

Host: Unknown.

Distribution: India (West Bengal).

Remarks: This new species does not fit the key to the species of Wijesekara \& Schauff (1994). It comes near Platyplectrus coracinus Wijesekara and Schauff, but differs from it in having: 1) frons not separated from vertex by a short transverse carina (in $P$. coracinus frons separated by a short transverse carina); 2) basal half of metasoma brownish yellow (in P. coracinus basal half of metasoma dark brown); 3) Head width $1.44 \mathrm{x}$ its length in anterior view (in $P$. coracinus head width $1.2 \mathrm{x}$ its length); 4) Malar space $0.3 x$ eye height (in $P$. coracinus malar space $0.5 x$ eye height); 5) F1 $1.44 \mathrm{x}$ as long as pedicel (in $P$. coracinus F1 $1.8 \mathrm{x}$ as long as broad); 6) $\mathrm{F} 11.63 \mathrm{x}$ as long as broad (in $P$. coracinus $\mathrm{F} 13 \mathrm{x}$ as long as broad); 7) F2 to F4 subequal in length and width (not so in $P$. coracinus, progressively wider towards clava); 8) Clava subequal in length to F1 (in P. coracinus clava shorter than F1); 9) Head in dorsal view $2.5 \mathrm{x}$ as broad as long (in $P$. coracinus head in dorsal view $2 \mathrm{x}$ as broad as long); 10) POL $1.25 \mathrm{x}$ OOL (in P. coracinus $1.4 \mathrm{x}$ as long as OOL); 11) Axillae not distinctly aciculate (in $P$. coracinus axillae distinctly aciculate); 12) Scutellum distinctly and finely reticulate (not so in $P$. coracinus); 13) Hind coxa not very smooth, weakly reticulate on dorsal side (well reticulate on latero-dorsal side in $P$. coracinus); 14) Longer spur of hind tibia distinctly shorter than first two tarsal segments (in P. coracinus longer spur as long as combined length of first two segments); 15) MV 3x as long as STV (in $P$. coracinus MV 3.7x as long as STV).

From India, two species are so far known, namely, Platyplectrus kuriani Wijesekara \& Schauff and Platyplectrus viridiceps (Ferriere) (Ferriere, 1940; Wijesekara \& Schauff, 1994; Noyes, 2004).

\section{REFERENCES}

Boucek, Z. (1988). Australasian Chalcidoidea (Hymenoptera). C.A.B. International, Wallingford, U.K. 832p.

Ferriere, C. (1940). On some parasites and hyperparasites of Artona catoxantha. Hamp. Bull. Ent. Res. 31: 131-139.

Girault, A.A. (1915). Australian Hymenoptera Chalcidoidea - IV (Supplement). Memoirs of Queensland Museum 3: 180-299.

Hayat, M. (1985). Family Eulophidae, pp. 246-252. In: Subba Rao, B.R. \& M. Hayat (Eds.). The Chalcidoidea (Insecta: Hymenoptera) of India and the Adjacent Countries. Part I- Review of Families and Keys to Families and Genera. Oriental Insects 19: 161-310.

Noyes, J.S. (2004). Universal Chalcidoidea Database. www.nhm.ac.uk/ entomology/chalcidoids.

Schauff, M.E., J. LaSalle and L.D. Coote (1997). Eulophidae pp. 327-429. In: Annotated key to the genera of Nearctic Chalcidoidea (Hymenoptera). National Research Council of Canada, Monograph Publishing Programme, 749pp. Wijesekara, G. A.W. and M.E. Schauff (1994). Revision of the tribe Euplectrini of Sri Lanka (Hymenoptera: Eulophidae). Oriental Insects 28: 1-48.

\section{ACKNOWLEDGEMENTS}

We are grateful to Prof. M. Hayat, Aligarh Muslim University and Dr. Bijankumar Das, Bidhan Chandra Krishi Viswavidyalaya, Mathurapur, West Bengal for sending Hayatiola and Omphalentedon and several other Chalcidoids for our studies. We thank the authorities of University of Calicut for facilities to work. 